\title{
A PROVA DE REDAÇÃO COMO UM DESAFIO ÉTICO: O CASO DO VESTIBULAR DA UERJ
}

\section{THE COMPOSITION EXAMINATION AS AN ETHICAL CHALLENGE: THE CASE OF THE PRE-ENTRANCE EXAMINATION TO RIO DE JANEIRO STATE UNIVERSITY}

\author{
Gustavo Bernardo \\ Universidade do Estado do Rio de Janeiro \\ Rio de Janeiro, Rio de Janeiro, Brasil \\ Isabel Cristina Rodrigues \\ Universidade do Estado do Rio de Janeiro \\ Rio de Janeiro, Rio de Janeiro, Brasil \\ Bruno Deusdará \\ Universidade do Estado do Rio de Janeiro \\ Rio de Janeiro, Rio de Janeiro, Brasil
}

RESUMO: Neste artigo, propomos uma reflexão acerca das alterações de caráter acadêmico promovidas, a partir de 2016, na prova de redação do Vestibular Estadual, organizado pela Universidade do Estado do Rio de Janeiro (UERJ). Com o objetivo de explicitar a complexa rede de práticas de linguagem em que se inscrevem os diferentes atores no contexto dessa prova, com ênfase em seu processo de correção, usamos como chaves amplas de análise a noção de dialogismo (BAKHTIN, 2004) e de educação pelo argumento (KRAUSE; CARVALHO, 2000). Nesse percurso, procuramos ressaltar de que modo as dimensões linguística e ética se articulam na construção de um processo avaliativo.

PALAVRAS-CHAVE: Vestibular; Redação; Usos de linguagem.

ABSTRACT: This article puts forward critical reflection on the academic changes implemented, as of 2016, in the Composition test of the pre-entrance examination to Rio de Janeiro State University. Aiming at making explicit the complex network of language practices in which the different social actors that take part in the context of the composition test engage, with emphasis on its evaluation, the authors use, as broad analytical tools, the notions of active responsive understanding (BAKHTIN, 2011) and that of argument-based education (KRAUSE; 
CARVALHO, 2000). This way, the researchers attempt to stress how both linguistic and ethical dimensions are put together in the construction of an evaluative process.

KEYWORDS: Pre-entrance examination; Composition; Language uses. 


\section{INTRODUÇÃO}

Diferentemente do que se possa imaginar, não é natural a existência de uma prova de redação nos concursos de acesso às universidades, os chamados vestibulares (do latim vestibulum, que significa entrada). Na década de 1970, esse ingresso, atendendo à lei $\mathrm{n}^{\mathrm{o}} 5.540 / 1968$, era feito por vestibulares unificados, cujas provas continham apenas questões de múltipla escolha.

Os efeitos negativos dessas avaliações, sem a expressão escrita, logo se fizeram sentir, tanto nos cursos superiores, pelas dificuldades apresentadas pelos que neles ingressavam, quanto nas práticas escolares, que começaram a abandonar atividades amplas de leitura e escrita. Respondendo a cobranças de setores da sociedade, em especial universidades, o decreto $\mathrm{n}^{0}$ 79.298/1977 obrigou a inclusão de prova ou questão de redação nos vestibulares (para mais detalhes, recomendamos CASTRO, 2008).

A partir de meados da década de 1980, as universidades passaram progressivamente a implementar perfis próprios de vestibular - cobrando redação. Por mais que esse tipo de prova, nos chamados "concursos de massa", envolvesse maiores gastos, por conta das equipes de correção, e discussão permanente acerca do que se considera "subjetividade" na atribuição de notas, entendeu-se que a universidade precisava (e ainda precisa) sinalizar que é imprescindível ensinar a escrever

A UERJ acompanhou esse movimento organizando seu Vestibular Estadual, com duas fases de provas: o Exame de Qualificação, com questões de múltipla escolha, e o Exame Discursivo, no qual se inclui a redação. A partir de 2016, algumas mudanças foram propostas para o conjunto desse processo seletivo, interessando-nos, no presente artigo, os deslocamentos realizados nas práticas de linguagem implicadas na complexa rede de produção e avaliação da redação.

Considerando tais deslocamentos, propomos uma reflexão em três eixos: discussão inicial sobre a concepção de linguagem subjacente às situações de interlocução envolvidas nessa rede, com ênfase para o princípio de endereçamento da palavra e da polifonia (BAKHTIN, 2011, 2013); tendo como referência essa discussão, apresentação das mudanças realizadas no Vestibular Estadual e dos impasses que as originaram; caracterização das tensões envolvidas na situação de avaliação das redações, articulando-as a questões de linguagem constitutivas desse processo. Nas considerações finais, com base na noção de educação pelo argumento (KRAUSE; CARVALHO, 2000), destacamos o caráter de "meta-redação" presente no escopo dos deslocamentos propostos pela UERJ.

\section{DA CONCEPÇÃO DE LINGUAGEM}

Definimos, como ponto de partida, que tanto a produção textual da redação pelo candidato quanto sua avaliação pelos profissionais que compõem a banca de 
correção configuram situações de interação verbal, que se inscrevem em contexto institucional específico.

Nas conversações cotidianas consideradas "primárias" (BAKHTIN, 2011), a palavra circula entre interlocutores e "é determinada tanto pelo fato de que procede de alguém, como pelo fato de que se dirige para alguém" (BAKHTIN, 2004, p. 113, grifos do autor). O endereçamento da palavra em relação ao interlocutor torna-se assim o primeiro aspecto a ser levado em consideração quando se adota uma orientação de análise fundada na interação verbal, em situação concreta. Rejeita-se, dessa maneira, uma clássica distribuição de papéis, repartida entre emissor-ativo e receptor-passivo. Considerar o endereçamento como princípio teórico significa ressaltar que "a palavra é o território comum do locutor e do interlocutor" (BAKHTIN, 2004, p. 113).

Nas interações de natureza "secundária", como na interlocução realizada na elaboração de redação pelo estudante, concorrem expectativas variadas, em relação às quais esse "território comum" se define, como, por exemplo, orientações dadas pelo professor, sinalizações fornecidas pela escola a respeito de seu projeto pedagógico e sua relação com atribuição de notas. No vestibular, essa interlocução, ainda que se assemelhe à realizada em âmbito escolar, atualiza coerções de um concurso público, cujo sigilo de participação e, por consequência, o desconhecimento entre os pares da interação se evidencia como uma de suas condições.

Wilson e Venturi (2013, p. 37) destacam, nesse sentido, aspectos que transcendem a situação de realização da prova: "o cenário de ensinoaprendizagem da escrita; os discursos instituídos pelas práticas e convenções das diversas instâncias sociais; e as projeções dos escreventes no momento da sua produção". Nesse contexto específico, o "território comum" a que se referia Bakhtin se configura a partir de pistas que procedem de origens diversas: orientações fornecidas não só nas salas de aula de escola ou curso preparatório), mas também em materiais específicos, como os documentos que organizam o concurso; relatos de experiências anteriores; sugestões de familiares e amigos que conhecem ou não as etapas do certame; representações midiáticas, entre outras.

Ao assumir a premissa do endereçamento da palavra, podemos minimamente visualizar a densa rede de discursos que se articula, tanto no momento de elaboração da redação pelo candidato, quanto no momento em que um profissional a avalia. Centrando-se na atividade do candidato, Wilson e Venturi (2013, p. 41-42) afirmam que "o vestibulando apresenta em seu texto uma série de representações a respeito da proposta temática, do avaliador (interlocutor), da situação comunicativa (o evento), de si mesmo e da própria escrita". Parece-nos possível assumir que processos semelhantes ocorrem no momento da correção: o avaliador, a partir de sua formação profissional e experiência no magistério, constrói representações a respeito da imagem de estudante esperada pela instituição, das habilidades de construção textual, dos valores éticos, do domínio do gênero, do registro considerado padrão, de si próprio como avaliador etc.

Note-se que a presença desses vários aspectos não se realiza de modo homogêneo. $\mathrm{O}$ conhecimento dos documentos prescritivos não se atualiza da 
mesma maneira por todos os candidatos, assim como as orientações de professores, materiais didáticos, vídeos disponíveis e páginas eletrônicas. Tal dispersão amplifica a complexidade da inscrição institucional exposta anteriormente e nos permite colocar em cena outro conceito imprescindível: a polifonia. De acordo com Bakhtin (2013, p. 23), "a essência da polifonia consiste justamente no fato de que as vozes aqui permanecem independentes e, como tais, combinam-se numa unidade de ordem superior à da homofonia". Recuperando os termos dessa metáfora, a dissonância entre as vozes não se realizaria sob uma orquestração única, pretensamente submetida ao projeto, por exemplo, de um narrador. Nesses termos, segundo esclarece o autor, as diferentes "vozes" ("convicções", "pontos de vistas acerca do mundo") encontram-se sem que haja uma expectativa de neutralização das diferenças que as constituem: "a polifonia pressupõe uma multiplicidade de vozes plenivalentes nos limites de uma obra" (BAKHTIN, 2013, p. 39).

Sem deixar de observar posicionamentos que consideram empregos muito específicos desse conceito ( $c f$. MACIEL, 2016), optamos por assumir a polifonia como um princípio constitutivo das práticas de linguagem. Considerar que a tomada da palavra se realiza sempre por um ato dirigido a outro torna-se assim princípio teórico ao qual se articula outra discussão: aquela que assume que toda palavra é marcada pelo eco constitutivo de outras palavras.

Até o momento, reunimos duas premissas fundamentais para análise das práticas de linguagem: i) toda palavra é dirigida a alguém; ii) os textos são constituídos por pontos de vista diversos. Essas premissas serão desdobradas por M. Bakhtin em estudos que sustentam que todos os enunciados - e não apenas os literários - configuram formas relativamente estáveis, que o próprio autor denomina de "gêneros do discurso" - em uma explícita ampliação da noção de "gêneros literários":

O emprego da língua efetua-se em forma de enunciados (orais ou escritos) concretos e únicos, proferidos pelos integrantes desse ou daquele campo da atividade humana. Esses enunciados refletem as condições específicas e as finalidades de cada referido campo não só por seu conteúdo (temático) e pelo estilo da linguagem, ou seja, pela seleção dos recursos lexicais, fraseológico e gramaticais da língua, mas, acima de tudo, por sua construção composicional (BAKHTIN, 2011, p. 262).

No trecho, o autor ressalta o vínculo indissociável entre o enunciado e as condições que o tornam possível. Os diversos campos da atividade humana fornecem coerções que, de certo modo, integram a materialidade dos enunciados. Como lembra Sobral (2009, p. 123), em Bakhtin, os "aspectos discursivos são derivados de sua definição filosófica como princípio geral do agir - só se age em relação de contraste com relação a outros atos". No que tange às provas de redação, essas coerções se explicitam, por exemplo, na demanda por certa extensão dos textos, por um exercício argumentativo, pelo emprego "formal" da língua, por encadeamentos textuais requeridos. 
Se os usos da noção de gênero do discurso têm enfatizado seus aspectos estáveis, como afirma Szundy (2014), a nosso ver, a estabilidade sempre relativa dos gêneros sugere contorno produtivo a respeito das práticas de produção e de compreensão de textos. Longe de se restringir a atitude meramente receptora, os falantes envolvidos nas situações de troca verbal reconhecem indicadores do posicionamento contido nos enunciados. Como destacamos, antes mesmo de ter acesso ao tema da redação, o candidato inscreve-se em uma ampla rede de enunciados que compõem essa interlocução - desde sua decisão de fazer o concurso e adquirir os materiais para efetivar sua participação, até orientações, sugestões, relatos, opiniões, entre tantos outros textos, que integram direta ou indiretamente as práticas de preparação do candidato.

Se dizíamos que o candidato não apenas "recebe" um tema em relação ao qual deve preparar um texto argumentativo, tal reflexão encontra, portanto, fundamentação produtiva no entendimento que Bakhtin expressa a respeito da compreensão de qualquer texto. Para ele, compreender um enunciado supõe a capacidade de se posicionar diante dele: "toda compreensão é prenhe de resposta..." (BAKHTIN, 2011, p. 271).

$\mathrm{Na}$ outra ponta dessa prática institucional de seleção, ainda ensejada pela desproporção entre número de vagas em cursos superiores públicos e número de candidatos a elas, a instituição que avalia também deve apresentar uma atitude responsiva diante dos resultados do concurso que propõe. No que diz respeito à prova de redação, sua participação vai além da proposição de temas de relevância social. Há desafios presentes na imagem que se constrói do ato de escrever e nos procedimentos de avaliação dessa escrita, como veremos a seguir.

\section{DAS MUDANÇAS NO VESTIBULAR ESTADUAL}

A UERJ, em 2016, implementou um conjunto de mudanças em seu Vestibular Estadual: i) inclusão de um texto inicial no Exame de Qualificação para o qual todas as áreas de conhecimento formulam questões; ii) introdução nos dois Exames de uma lista de livros, a princípio de literatura, escolhida a partir de consulta pública, amplamente divulgada na página da Revista Eletrônica do Vestibular UERJ; iii) separação da redação da prova de Língua Portuguesa Instrumental; iv) correção da redação por banca própria; v) adoção de método holístico nessa correção. Interessam-nos especialmente as alterações indicadas em iii, iv e v.

Durante pelo menos duas décadas, no Exame Discursivo, todos os candidatos fizeram uma prova de redação conjugada à de Língua Portuguesa Instrumental. A vantagem dessa combinação residia na antecipação do "território comum" (BAKHTIN, 2004), com os textos utilizados na prova instrumental encaminhando o debate para a elaboração da redação.

Ao lado desse mérito, porém, a solução de unir essas provas acabou revelando duas desvantagens. A primeira, mais evidente, é certa invisibilidade da nota de redação, na medida em que ela se combinava a uma outra. Tampouco então, essa nota sozinha poderia desclassificar um candidato. A redação acabava 
não oferecendo uma perspectiva, na sua devida singularidade, como instrumento de medida. A segunda desvantagem, cuja percepção só foi possível a partir de uma análise de resultados ao longo dos anos, residia no próprio processo de correção, não só em sua dimensão operacional, mas também de concepção de aplicação de critérios de avaliação.

Com a correção simultânea da redação e da prova de Língua Portuguesa Instrumental, observava-se que a tarefa dos avaliadores era alternada entre um momento de correção de cinco questões de análise textual, com respostas de duas a três linhas, e outro de correção de um texto argumentativo, desenvolvido em vinte a trinta linhas. Trata-se de posturas de avaliação diferenciadas, inclusive com modos de atribuição de pontuação distintos, o que acrescentava complexidade à tarefa.

A análise dos resultados obtidos na prova de redação, em separado, evidenciou o seguinte cenário: a distribuição das notas atribuídas concentrava-se entre 6.2 e 6.9 , com um número limitado de notas próximas de 0.0 ou de 10.0 , de acordo com relatórios do Departamento de Seleção Acadêmica, órgão da Subreitoria de graduação da Universidade (DSEA/SR-1/UERJ) ${ }^{1}$. A redação parecia, assim, cumprir com alguma restrição sua função de classificação de candidatos.

Para além do aspecto mais operacional, de organização do trabalho de correção focando questões e redações simultaneamente, começou-se a observar também que o processo de atribuição de pontuação à redação, por meio do método analítico (ver detalhes adiante), provocava fragmentação indesejada da leitura. A avaliação da qualidade de um texto envolve número grande de variáveis, que, por sua vez, combinam-se de maneira diferente em cada redação. Os relatórios de dados da correção vinham indicando que o método analítico induz os corretores a encontrar um meio-termo nos itens avaliados. No caso da UERJ, como eram cinco itens, cada um valendo 2,0 , as notas se concentravam em 1.0 e 1.5 .

Foi com o intuito de buscar soluções para esses problemas que o DSEA decidiu pela separação da prova de redação da prova de Língua Portuguesa Instrumental. A redação passou a ser corrigida por banca própria e por meio de método holístico. Na seção 4, caracterizamos esses deslocamentos, retomando a discussão acerca das práticas de linguagem.

\section{DA AVALIAÇÃO DA REDAÇÃO}

Como se sabe, uma das etapas do processo de elaboração de qualquer prova é estabelecer os critérios de sua correção. Nas provas objetivas, com questões de múltipla escolha, corrigir é um ato de verificação/conferência de respostas. As provas discursivas, por sua vez, apresentam questões cujas respostas

\footnotetext{
${ }^{1}$ Agradecemos à professora Gisele de Carvalho, coordenadora acadêmica do DSEA/SR-1/UERJ, pela entrevista que nos concedeu em 11/12/2017, fornecendo dados que permitiram a concretização deste trabalho.
} 
são produzidas por escrito. $\mathrm{O}$ ato de corrigir, aqui, requer que se analise se dada formulação atende a uma expectativa de resposta. Essa expectativa costuma ser apresentada sob a forma de "padrões de resposta". Por se tratar de um processo de análise - e não de conferência -, quem faz a correção da prova é necessariamente inserido em um contexto em que a "variação no julgamento", habitualmente chamada apenas de "subjetividade", faz-se presente, em maior ou menor grau.

Assim como há diferentes tipos de questões de múltipla escolha, há também diferentes tipos de questões discursivas, com padrões de respostas mais ou menos fechados. Mesmo os padrões mais fechados colocarão dilemas para um corretor, convocando-o a tomadas de decisões. Para a correção em larga escala, apenas a construção criteriosa de padrões de resposta e a preparação de banca qualificada para aplicar esse padrão pode neutralizar flutuações de julgamento das respostas e garantir a confiabilidade dos resultados - construção e preparação que necessariamente vão se deparar com uma complexidade específica, que é da ordem da linguagem, da ordem do "território comum" que se cria.

Na prova de múltipla escolha, oferecer uma resposta correta é, em certa medida, um gesto de repetição: após os procedimentos de solução da questão, tendo em vista que a resposta já está formulada, é necessário reconhecer a forma como o avaliador a apresenta. Nas questões discursivas, não se pode contar com essa "repetição".

Na perspectiva dialógica (BAKHTIN, 2004, 2011), a prova de natureza discursiva, que configura certo gênero, constrói um espaço sócio-histórico comum entre examinador e examinado, pelo qual se presume que irão circular enunciados estabilizados, relativos à produção científica de uma dada área de conhecimento. Supõe-se que aquele que faz a prova expresse um domínio desses enunciados, inseridos no gênero "prova". Tal expressão, porém, trará sempre as marcas de quem enuncia: a compreensão daquele conhecimento e a apropriação do gênero no âmbito de sua inserção social. Em uma prova discursiva, portanto, quem corrige precisará estabelecer mecanismos que lhe permitam identificar o "mesmo" - enunciados relacionados a uma dada área de conhecimento - na singularidade da expressão escrita de "um outro".

$\mathrm{Na}$ correção da redação, esse processo se torna ainda mais complexo, pois não há sequer um padrão de resposta: será preciso, na análise de um texto que atende a algumas coerções, reconhecer um processo de argumentação válido e suficiente. Neste terceiro universo de questão, o ato de corrigir requer, sobretudo, a possibilidade de dialogar com as muitas perspectivas de compreensão do tema proposto.

Ao longo do tempo, diferentes processos de correção de redação têm definido dimensões da linguagem a serem avaliadas. O modo de organização dessas dimensões, com seu tradicional desdobramento em itens, estabelece critérios para pontuar o texto produzido. Esses critérios são chamados com frequência, quase nunca oficialmente, de "grade de correção", pela sua apresentação habitual no formato de uma tabela. A metáfora presente na palavra "grade" indica que, para avaliar, é preciso discriminar um conjunto de índices da produção textual, isolando-os. Aquilo que configura um todo - o texto - é desarticulado para que se possa preencher a tabela e atribuir uma nota. 
Vianna (1978, p. 29) relata um estudo da Fundação Carlos Chagas cujo objeto era a definição de "um critério que permitisse uma correção homogênea de milhares de redações". E o critério estabelecido naquele momento foi o da partição da pontuação em itens de avaliação, com a seguinte justificativa:

(...) atribuindo valores parcelados a estrutura, conteúdo e expressão, o critério buscou fornecer aos avaliadores instrumentos mais precisos para o julgamento do texto como um todo. Os três itens são faces diversas do mesmo objeto, que é a prova total como se apresenta em sua redação final, resultante de um processo de elaboração em que o candidato deverá ter considerado necessariamente esses três aspectos. (VIANNA, 1978, p. 30)

Os resultados do estudo, porém, não permitem estabelecer relações diretas entre o uso de tal critério e a "precisão" pretendida, como alerta o autor em suas conclusões. Com a referência a esse estudo, de caráter inaugural, chamamos atenção para certa fragilidade na associação, relativamente disseminada, entre correção de redação baseada na divisão em "itens de avaliação" e baixa flutuação no julgamento ou, como usualmente se refere, maior objetividade.

Matos (2014) aponta a escassez de pesquisas na área de educação que investiguem a validade e confiabilidade de resultados de avaliação. No que diz respeito à correção de redações em larga escala, o autor apresenta uma distinção entre o método "analítico" e o "holístico":

O método holístico consiste basicamente em atribuir um escore único com todos os critérios da avaliação considerados conjuntamente (exemplo: tema, coesão e ortografia). Já no método analítico, as redações não recebem apenas uma nota geral. Os avaliadores atribuem notas em diversos critérios, que combinados geram um escore final. (MATOS, 2014, p. 308-309)

No Vestibular Estadual, o método analítico de correção foi a opção privilegiada por cerca de duas décadas. Desde 2007, seus itens de avaliação se mantiveram bastante estáveis: adequação do tema; tipo de texto; desenvolvimento da argumentação; coesão e estrutura do período; registro. Durante o primeiro dia de correção do Vestibular Estadual, a banca corretora, que trabalha presencialmente, analisa redações de candidatos. As notas atribuídas são debatidas e são estabelecidos conjuntamente "pontos de ancoragem" para orientar o modo de avaliar cada item - processo repetido na análise de casos de discrepância. Tomamos a expressão aspeada de empréstimo a Matos (2014), ao aludir a discordâncias entre avaliadores (“juízes”) na pontuação de um determinado critério: 
Uma das possíveis explicações para a diferença entre confiabilidade e concordância é a utilização de pontos de ancoragem distintos. Por exemplo: juízes realizando classificações em uma escala de 1 a 10 . Imaginemos que o juiz 1 avalia todos os sujeitos com escores altos na parte superior da escala (entre 5 e 10) e o juiz 2 avalia todos com escores baixos (entre 1 e 5 na escala). Numa situação como essa, precisamos definir se a variabilidade individual do juiz é importante para os fins de uma dada pesquisa. (MATOS, 2014, p. 304)

Como se observa, uma situação como a citada poderia não configurar problema se o objetivo da avaliação fosse conhecer, em um conjunto de redações, a posição relativa de cada uma delas. Para concursos classificatórios, porém, coincidência entre pontos de ancoragem importam, e estes podem ser definidos, no contexto que analisamos, como acordos produzidos sobre de que modo interpretar - e pontuar - as diferentes formas de expressão dos candidatos nos itens em avaliação. Essa é uma dinâmica que procura promover uma avaliação o mais equânime possível. Assim, o "território comum" da linguagem precisa se estabelecer em pelo menos dois níveis: não só entre examinador e examinado, mas também entre examinadores.

Em termos bakhtinianos, pode-se dizer que a leitura da redação de vestibular impõe uma atitude responsiva de mensuração. Mas até que ponto, mesmo com o cuidado em estabelecer os devidos pontos de ancoragem, mensurar separadamente itens que compõem a textualidade, base dos métodos analíticos, garante a postura dialógica à qual vimos nos referindo?

Foi com base nessa indagação, de fundo técnico e ético, que os critérios de correção das redações do Vestibular Estadual passaram a ser organizados de acordo com uma concepção holística, distribuídos em seis graus, com suas respectivas faixas de pontuação. Cada grau indica o desempenho do candidato, ao produzir seu texto, em relação às seguintes de dimensões da linguagem, tomadas em conjunto: compreensão do tema; domínio do gênero; coerência na construção do argumento, com apresentação de posicionamento crítico pessoal; organização das partes do texto; uso dos recursos de coesão, com indicação de soluções pessoais de estilo; conhecimento da norma-padrão.

Essa abordagem se aperfeiçoa pela descrição da expectativa de interpretação para cada grau, a cada proposta de redação - a base dos pontos de ancoragem. Os tópicos da descrição são necessariamente intercambiáveis, porque, ao se combinarem em cada texto, fazem com que um aspecto negativo ou positivo não o seja sempre, dependendo da relação estabelecida com os demais elementos textuais. Empregado na correção das redações nas duas últimas edições do concurso, o método holístico produziu uma curva de notas com melhor distribuição dos graus atribuídos, sem concentração da pontuação em uma faixa mediana, como vinha acontecendo com o método analítico.

Uma análise preliminar desses resultados indica a necessidade de explicitar a tensão constitutiva do trabalho de avaliação, em especial nas correções em larga escala, em dois âmbitos: de um lado, a contenção de julgamentos fora dos pontos de ancoragem; de outro, a afirmação de que a correção não deve escamotear um 
ato autêntico de leitura. A assunção dessa perspectiva parece devolver aos professores que corrigem a confiança na própria experiência pedagógica para distinguir entre diferentes desempenhos nas redações.

\section{CONSIDERAÇÕES FINAIS}

Como sinaliza Krause (1985), quem escreve reaprende a escrever a cada texto que produz, e esse é um dos motivos por que uma redação é única e deve ser avaliada a partir das próprias premissas, resistindo à segmentação em partes. Às vezes, os alunos se entusiasmam com o que escrevem, afirmando que não sabiam que "tinham" aquelas ideias dentro da cabeça. Na verdade, não tinham. Apenas graças ao próprio ato de escrever, puderam construir e pensar aquelas ideias.

A redação representa, portanto, um momento privilegiado de aprendizagem, porque o candidato não apenas mostra sua capacidade de redigir um texto e construir um argumento, como também aprende ou reaprende a pensar sobre o tema proposto, dessa maneira descobrindo uma nova perspectiva no mundo e sobre o mundo. Ainda que um concurso possa esvaziar esse sentido da escrita, ele continua agindo. E não são apenas os concursos que promovem tal esvaziamento - muitas vezes, são os próprios sistemas de ensino que têm dificuldade, ou não desejam trazer para as suas práticas cotidianas tal valor radical do ato de escrever. Desse modo, os deslocamentos empreendidos no Vestibular Estadual, e o debate que promovem, parecem-nos caminhar no sentido não só de tornar a correção da redação mais precisa e justa, mas também de tornála significativa como processo de aprendizagem para todos os envolvidos, lançando luz sobre práticas de linguagem envolvidas em situações de avaliação.

No primeiro semestre de 2017 , em virtude da grave crise instaurada pelo governo do estado do Rio de Janeiro, a UERJ cancelou a prova de Língua Portuguesa Instrumental, para a qual os candidatos deveriam ler Dom Casmurro. Como a redação foi mantida, e se desejava manter a leitura, anunciou-se que o tema da redação seria uma questão polêmica levantada pelo romance. A solução de associar tal leitura à prova de redação acabou configurando nova mudança, não planejada: a proposta restringiu a gama de temas possíveis apenas àqueles levantados no enredo do livro, inscrevendo a análise do romance como condição para a configuração do "território comum" entre a banca, os candidatos e demais atores envolvidos nessa rede. Tal mudança produziu efeitos em diferentes níveis: i) da relação com a leitura de um romance canônico, do qual não se extraem apenas questões interpretativas; ii) da vinculação da literatura com o mundo, na medida em que o tema proposto não se restringe ao universo da obra, projetandoa para pensar seu entorno (ver anexo); iii) da presença de outros textos na redação do candidato, visto que a tensão entre menção e autoria é agora explicitamente apresentada como horizonte de escrita.

Antes de se concluir pela relação entre o tema da redação e a leitura do romance, o DSEA já havia realizado, ao longo de 2017, outro dispositivo de alargamento das margens de produção/circulação de textos: a realização de um Ciclo de Palestras sobre os livros indicados ao Vestibular Estadual (disponível em 
ciclodepalestras.dsea.uerj.br). Na palestra sobre Dom Casmurro, discutiram-se os possíveis debates levantados pela narrativa de Machado de Assis. Essa palestra recebeu por volta de sete mil acessos - número equivalente a um terço do total de candidatos que participaram do Exame Discursivo. Além da importância da iniciativa que leva a Universidade para além de seus muros, o Ciclo contribuiu para afastar o elemento "surpresa", enfatizando a avaliação como espaço de construção de conhecimento.

Nesse sentido, procurando se distanciar das práticas de "treinamento/adestramento" para elaboração da redação, o perfil do concurso investe no ato de escrita como espaço por meio do qual se ensina a pensar, a pesquisar, a investigar e a argumentar (KRAUSE; CARVALHO, 2000). Em síntese, "ensina" a inscrever-se, de maneira crítica, na comunidade de produção/circulação de textos que também nos definem como sociedade. Assim, ao propor as mudanças em tela, tratando, ainda que indiretamente, tanto do ensino de redação quanto dos modos pelos quais esse tipo de prova se insere em vestibulares, a UERJ parece construir uma experiência de meta-redação.

No momento em que se finaliza este artigo, os resultados das provas haviam acabado de ser divulgados. Ainda não há dados suficientes para uma análise completa dos efeitos desse novo modelo de prova e de sua correção. Ao trazer esta investigação em seu caráter ainda exploratório, desejamos deixar registrada, sobretudo, uma atitude de resistência. Em um contexto de degradação, imposto por políticas que preterem a educação pública, a Universidade mantém seu compromisso ético-político com a sociedade, avaliando a si mesma e renovando suas práticas no sentido de se tornar ainda mais democrática.

\section{REFERÊNCIAS}

BAKHTIN, M. Problemas da poética de Dostoiévski. Trad. de Paulo Bezerra. Rio de Janeiro: Forense Universitária, 2013.

Estética da criação verbal. Trad. de Paulo Bezerra. São Paulo: Martins Fontes, 2011.

. Marxismo e filosofia da linguagem: problemas fundamentais do método sociológico na ciência da linguagem. Trad. de Michel Laud e Yara F. Vieira. São Paulo: Hucitec, 2004.

CASTRO, M. M. C. e. As razões de uma ruptura: elementos para uma história da prova de redação nos exames vestibulares isolados da UFRJ - 1987/88-2007/08. Revista Contemporânea de Educação, Rio de Janeiro, v. 3, n. 5, 2008. Disponível em: https://revistas.ufrj.br/index.php/rce/article/view/1547. Acesso em: 17 jan. 2018.

KRAUSE, G. B. Redação inquieta. Porto Alegre: Globo, 1985. 
2000 .

; CARVALHO, G. de. Educação pelo argumento. Rio de Janeiro: Rocco,

MACIEL, L. V. de. C. Diferenças entre dialogismo e polifonia. Revista de Estudos da Linguagem, Belo Horizonte, v. 24, n. 2, 2016. Disponível em: http://www.periodicos.letras.ufmg.br/index.php/relin/article/view/8270 . Acesso: 28 jan. 2018.

MATOS, D. A. Confiabilidade e concordância entre juízes: aplicações na área educacional. Estudos em Avaliação Educacional, São Paulo, v. 25, n. 59, set.-dez. 2014.

Disponível

em:

$<$ http://publicacoes.fcc.org.br/ojs/index.php/eae/article/view/2750>. Acesso em: 17 jan. 2018.

SOBRAL, A. O conceito de ato ético de Bakhtin e a responsabilidade moral do sujeito. Bioethikos, v. 3, n. 1, 2009. Disponível em: $<$ http://www.saocamilosp.br/pdf/bioethikos/68/121a126.pdf. Acesso em: 20 jan. 2018.

SZUNDY, P. T. C. Educação como ato responsável: a formação de professores de linguagens à luz da filosofia da linguagem do Círculo de Bakhtin. Trabalhos em Linguística Aplicada, Campinas, v. 53, n.1, jan.-jun. 2014. Disponível em: $<$ http://www.scielo.br/pdf/tla/v53n1/v53n1a02.pdf > . Acesso em: 20 jan. 2018.

VIANNA, H. M. Aplicação de critérios de correção em provas de redação. Cadernos de Pesquisa, São Paulo, v. 26, 1978. Disponível em:

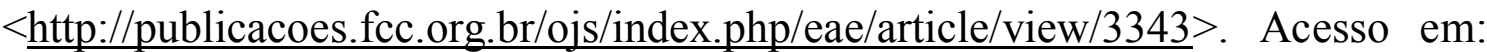
17 jan. 2018.

WILSON, V.; VENTURIM, A. P. da S. Saberes e interlocuções em redações de vestibular. Soletras, São Gonçalo, v. 26, n. 2, jul.-dez., 2013. Disponível em: $<$ http://www.epublicacoes teste.UERJ.br/index.php/soletras/article/view/9349/7884>. Acesso em: 26 jan. 2018. 


\section{ANEXO}

Eu era advogado de algumas casas ricas, e os processos vinham chegando. Escobar contribuira muito para as minhas estreias no foro. Interveio com um advogado célebre para que me admitisse à sua banca, e arranjou-me algumas procuraçóes, tudo espontaneamente.

(capitulo CIV)

No trecho acima, do romance Dom Casmurro, de Machado de Assis, Bento Santiago, o narrador-personagem, fala sobre sua profissão. O leitor, porém, não tem notícia de qualquer processo em que ele tenha atuado, se ganhou alguma causa, se perdeu. Entretanto, todo - romance pode ser compreendido como um longo Auto de Acusação que Bento move contra sua esposa, Capitolina Santiago, a Capitu, por adultério.

Atuando como promotor e juiz ao mesmo tempo, Bento considera Capitu culpada e a condena ao exílio na Europa até o dia de sua morte. Nesse processo, ela não tem direito à defesa, nem mesmo à voz. Sua versão dos acontecimentos não é apresentada.

A partir da leitura do romance, é possível refletir sobre o seguinte problema que faz parte do nosso cotidiano:

\section{a verdade pode ser estabelecida com base em uma única perspectiva?}

Escreva uma redação argumentativo-dissertativa, em prosa, com 20 a 30 linhas, discutindo esse problema.

Utilize a norma-padrão da língua portuguesa e atribua um título à sua redação, que deve ser escrita inteiramente com caneta e não deve ser assinada.

Fonte: DSEA/SR-1/UERJ (2018) $)^{2}$

${ }^{2}$ Disponível em: <http://www.revista.vestibular.uerj.br/arquivos/pdf/questao/31.pdf $>$. Acesso em: 26/01/2018. 
Gustavo Bernardo

GustavoBernardoKrause@gmail.com

Isabel Cristina Rodrigues

Isabe1060813@gmail.com

Bruno Deusdará

BrunoDeusdara@gmail.com

Recebido em: 22 fev. 2018

Aceito em: 31 maio 2018

Publicado em: 19 ago. 2018 